\title{
Plantio de Pinus elliottii em pequenas propriedades rurais no norte do Rio Grande do Sul
}

\author{
Pinuselliottii on small farms in the north of Rio Grande do Sul \\ jordana georgin' \\ 'Universidade Federal de Santa Maria, RS, Brasil
}

\section{Resumo}

O Pinus elliottiiconsiste em uma das mais importantes espécies de árvores atualmente utilizadas para plantações florestais no Brasil. A sua grande versatilidade, sua rusticidade e adaptabilidade, seu excelente ritmo de crescimento, aliados à qualidade da madeira e dos produtos com ela fabricados, têm feito com que o cultivo do Pinus seja um sucesso no Brasil. A região sul do Brasil por ter um clima totalmente favorável ao desenvolvimento da espécie, vem tendo um crescente aumento das áreas cultivadas com pinus, porém a agricultura tornou-se o principal empasse, tornando esta atividade ainda primária no meio rural. Sendo assim, o objetivo deste trabalho foi realizar um levantamento em cinco municípios da região norte do estado, totalizando 38 propriedades rurais, fazendo uma analise de como estão sendo implantadas essas áreas de pinus, e quais são os objetivos futuros dos produtores com esta atividade, além de outros pontos que puderam ser analisados.

Palavras-chave: Espécies florestais, propriedades rurais, Pinus elliottii.

\begin{abstract}
Pinuselliottii is one of the most important tree species currently used for forestry plantations in Brazil . Its great versatility, its hardiness and adaptability, its excellent growth rate, coupled with the quality of wood and products made with it, have caused the cultivation of Pinus be a success in Brazil. The southern region of Brazil for having a completely favorable climate for the development of the species, and has been a growing increase in areas planted with pine, but agriculture became the main standoff, making this even primary activity in rural areas. Thus, the aim of this study was to conduct a survey in five municipalities in the northern region of the state, totaling 38 farms , making an analysis of how these areas are being implemented pine, and what are the future goals of the producers in this activity , Amongst other things that could be analyzed.
\end{abstract}

Keywords: forestry species , farms , Pinuselliottii 


\section{INTRODUÇÃO}

O Pinus consiste em um dos mais importantes tipos de árvores atualmente sendo utilizadas para plantações florestais no Brasil. A sua grande versatilidade, sua rusticidade e adaptabilidade, seu excelente ritmo de crescimento, aliados à qualidade da madeira e dos produtos com ela fabricados, têm feito com que o cultivo do Pinus seja um sucesso no Brasil. Esse gênero florestal é originário das Américas do Norte e Central. No Brasil, foi inicialmente plantado nos estados do sul, principalmente os Pinus elliottiii e P. taeda, a partir dos anos 1940's. Com isso, cooperou para o crescimento das fábricas regionais de celulose, papel, serrarias, móveis, etc. Mais tarde, com a introdução dos Pinus tropicais, o Pinus espalhou-se por todo o país, sendo que seu reflorestamento ainda se encontra em expansão (PILAU et al., 2007).

Hoje, as estatísticas apontam cerca de 1,8 milhões de hectares plantados com Pinus no Brasil, com excelentes incrementos médios que variam de $20 \mathrm{a} 35 \mathrm{~m}^{3} /$ hectare.ano. A demanda por sua madeira e resina incentivam novos plantios, o que vem ocorrendo de forma contínua, mostrando a confiança do produtor florestal, rural e da indústria de base florestal (EMBRAPA, 1988).

Numa conceituação técnica, os cultivos de pínus podem ser classificados em tropicais e subtropicais. Na região sul do Brasil, apresenta elevado potencial para o cultivo da espécie pínus tropicais, especificamente o P. elliottiivar. P. taeda, com características importantes, tais como a facilidade de adaptação, a facilidade nos tratos culturais, o rápido crescimento, a rusticidade e a tolerância, possibilitando o plantio em solos marginais para a agricultura (BERTOLANI, 1980).

Apesar doPinuselliottii ser uma espécie pouco exigente em termos de fertilidade do solo, os cuidados no plantio e nos primeiros anos da floresta são essenciais para se alcançar bons incrementos, maior qualidade nas florestas e maiores lucros nas colheitas (desbastes e corte final, conforme o manejo). Logo, a escolha de mudas idôneas e de boa procedência, o conhecimento da base genética do material e os aspectos fitossanitários são medidas relevantes no início do cultivo dos Pinus. Posteriormente, o controle de pragas, da mato-competição, de patógenos, bem como a avaliação da nutrição mineral, são também características relevantes no manejo florestal (IPEF, 1976).

Paralelamente, a necessidade de aumento da produção de madeira para abastecer a indústria de madeira serrada, de lâminas, de painéis, de processamento mecânico e a de celulose e papel, foi um fator preponderante para a introdução do pínus no Brasil, num cenário onde a principal fonte de matéria-prima era araucária angustifolia.

Dessa forma, conforme relata Golfari (1978), citado por Kronka, Bertolani e Ponce (2005, p.13), o pínus estabeleceu-se como um importante aliado na preservação dos ecossistemas florestais nativos, pois a região apresenta as condições térmicas e hídricas consideradas satisfatórias para o seu desenvolvimento, ressalvando-se a necessidade do zoneamento ecológico, com a definição dos parâmetos das condições do solo, clima, altitude, relevo e vegetação original.

Nesse contexto, o reflorestamento de pínus surge como uma opção de investimento e pode auxiliar o pequeno agricultor no fortalecimento econômico, ou seja, na geração de uma nova renda, derivada de outra atividade, diminuindo assim a dependência financeira exclusiva das culturas tradicionais, e no fortalecimento social, pois uma nova renda permite a opção pela manutenção do homem no campo, evitando os efeitos danosos do êxodo rural (KWASNIESWSKI, 2008).

Assim, o objetivo deste trabalho foi realizar um levantamento de como estão sendo implantadas essas áreas de pinus, e quais são os objetivos futuros dos produtores com esta atividade.

\section{MATERIAL E MÉTODOS}

O presente estudo foi realizado na zona rural de municípios localizados ao norte do estado do Rio Grande do Sul,aonde foram visitadas propriedades pertencentes aos municípios de Sarandi, Palmeira das Missões, Ronda Alta, Constantina e Ronda Alta totalizando 38 propriedades. Segundo a classificação climática de Köppen, o clima da região é Cfa, ou seja, subtropical úmido com temperatura média anual de $19,1^{\circ} \mathrm{C}$, variando com máxima de 38 e mínimo de $0^{\circ} \mathrm{C}$.

Em todas as propriedades foram realizado um levantamento da área em que se estabeleciam esses plantios, além de um levantamento feito com os agricultores por meio de uma ficha a qual constava questionamentos referentes ao que os levaram a fazer uso dessa atividade, quais os objetivos 
esperados, os cuidados e técnicas de manejo que aplicaram na área, e se pretendem dar continuidade a esta atividade futuramente.

Todas as propriedades tinham como fonte de renda principal a agricultura, produção de grãos, sendo que a área maior e de melhor qualidade de solo e fertilidade eramdestinadas para este fim, notouse também uma fonte de renda muito unidirecional nas propriedades, onde as atividades ficavam muito dependentes da agricultura, analisando o histórico da região em anos de estiagem a econômica desses municípios ficava muito enfraquecida, visto que a zona urbana desses locais é fortemente dependente da agricultura, sendo este a principal economia dessa região.

Outro ponto marcante na região é a mecanização elevada dessas propriedades, aonde grandes propriedades dominam essas áreas, na sua maioria atividades como produção de leite, criação de suínos e avesé feito somente para consumo próprio, sendo que em muitas essas atividades são inexistentes, obrigando o produtor a obter esses alimentos nas cidades, esse ponto é bastante influenciado pela pequena distância existente estre a zona urbana e a rural, facilitando o fluxo nesse meio.

\section{RESULTADOS E DISCUSSÃO}

A região norte do Rio Grande do Sul a qual abrange os cinco municípios analisados, bem como as 38 propriedades, possuí características econômicas bastantes homogenias o que explica as situações comuns encontradas de um município para o outro. Um ponto importante observado foi que nenhuma propriedade teve contato com um profissional da área florestal para dar inicio ou até mesmo auxiliar no manejo do plantio, isso justifica a ocorrência da falta de um espaçamento continuo e inadequado à espécie. Ambas as áreas em que foram plantadas as mudas se tratavam de áreas com um solo de baixa fertilidade, com declives acentuados, sendo que muitas delas, devido ao plantio já ter uma idade avançada, já estava em consorcio com animais.

As figuras a seguir mostram como as áreas destinadas ao plantio dessa espécie florestal, são bastante declivosas, e com baixo potencial fértil, tornando-se assim improprias para a agricultura, outro fator que pode ser observado é a falta de um espaçamento adequado, além da inexistência de técnicas de sistematização na área, o que mostra o baixo investimento feito pelos produtores nessas áreas destinadas a silvicultura.
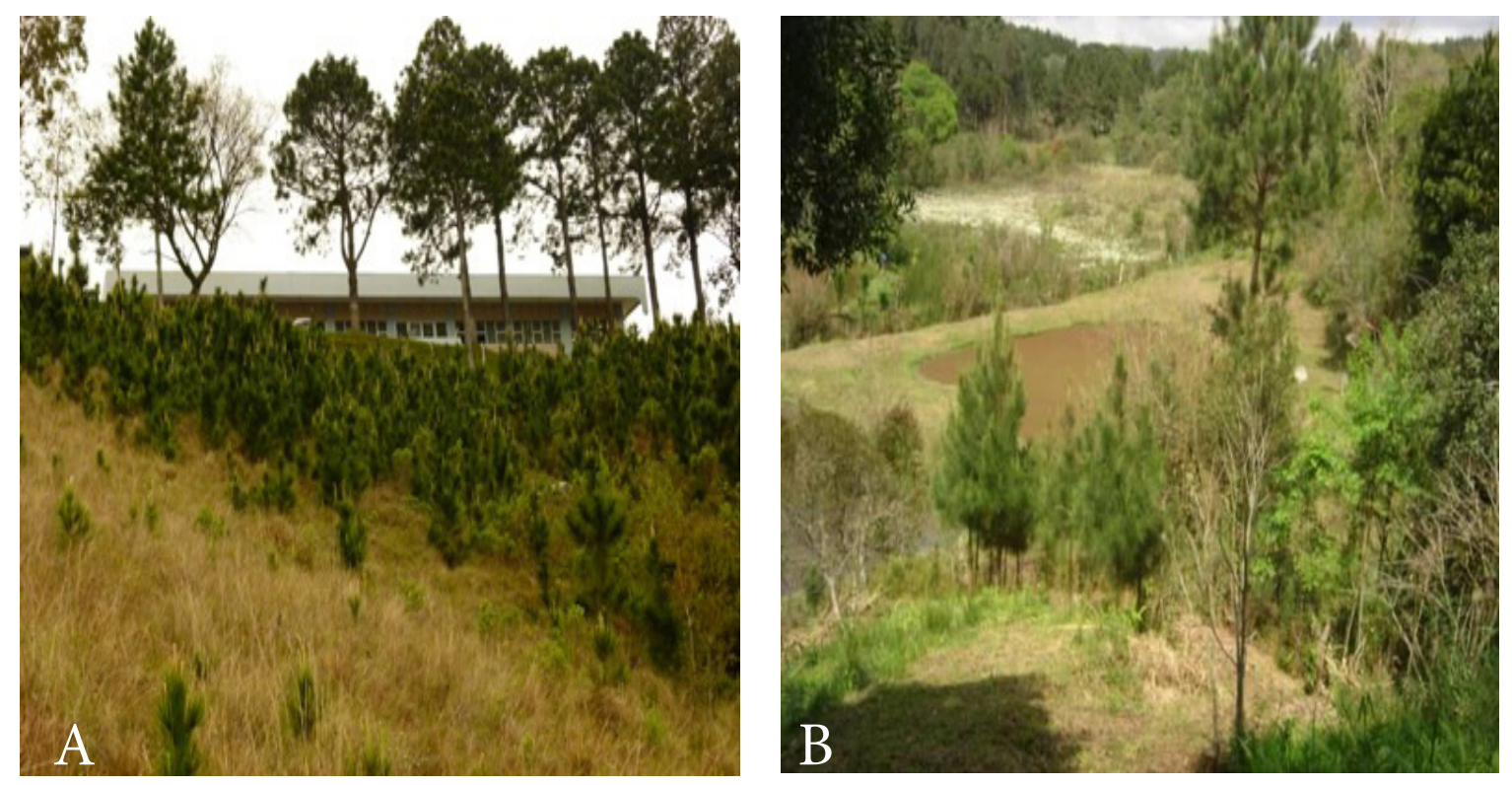

Figura 1(A e B) - Imagens das áreas utilizadas para o plantio de Pinus elliottii em propriedades da região.

Um ponto marcante foi à falta de conhecimento sobre a espécie cultivada, bem como a falta de interesse em se saber a procedência da muda, sendo que a maioria delas era adquirida nas próprias prefeituras locais, aonde observando as espécies pode-se notar certa ocorrência de indivíduos de Pinus 
taeda. Foi concluído que fatores como: exigência de um solo pouco fértil, grande resistência a geadas, serrarias presentes na região e pouco investimento inicial, foram o que levou os produtores a dar início a esta atividade. Comoa maioria das áreas não sofreram nenhum desbaste ainda, questionados sobre o futuro desta atividade muitos não souberam responder, afirmando que estão esperando a primeira colheita das áreas, porem muitos foram otimistas e por conhecimento de outros produtores pretendem futuramente aumentar a área de plantio. Somente três produtores irão fazer uso próprio da madeira como carvão, os demais irão abastecer as serrarias presente próximaà região, visto que estas compram a madeira em pé, sendo o corte e baldeio realizado por elas.

A Figura a seguir mostra as linhas de plantio de pinus presentes bem na beirada de estradas, bem como o incomum cuidado feito em uma área de plantio por meio da construção de uma cerca a fim de evitar entrada de animais no local.
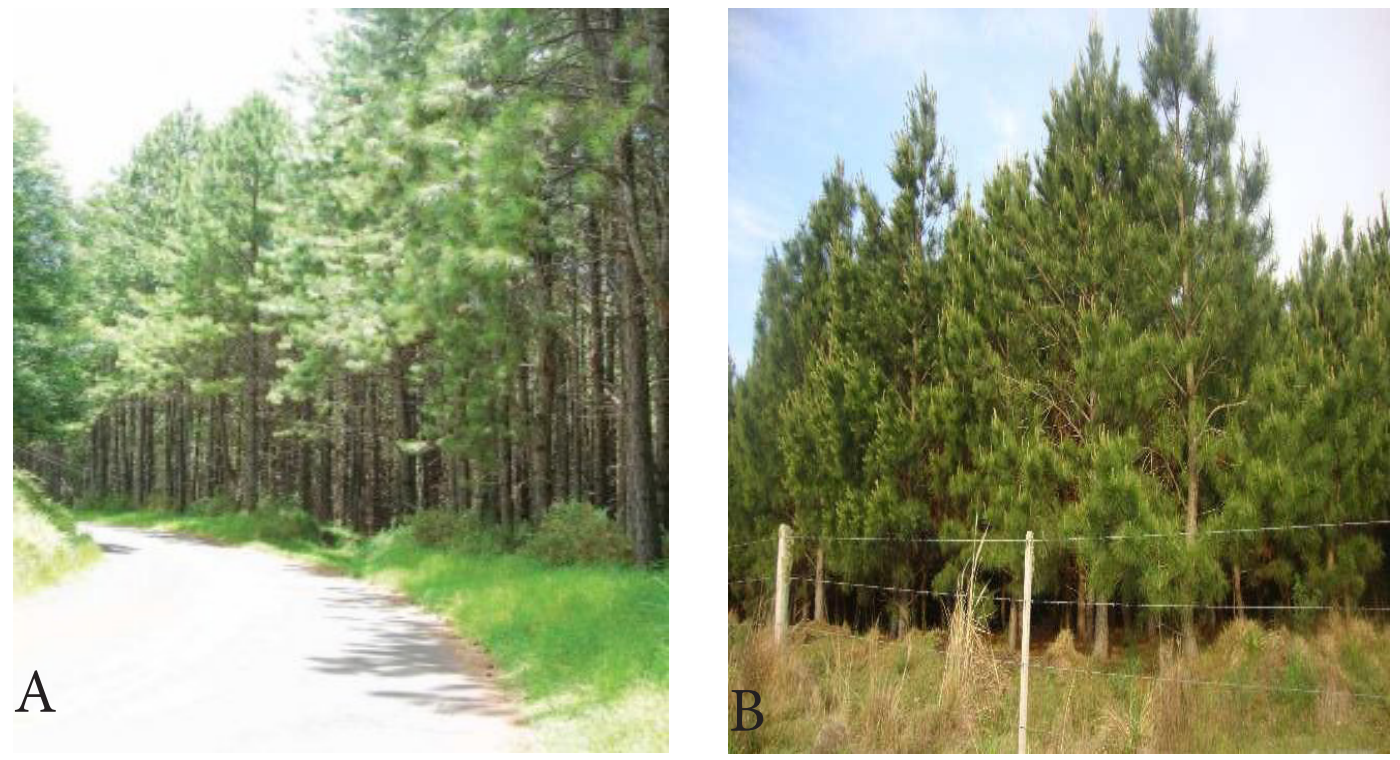

Figura 2 (A e B) - Presença de Pinus próximo á estrada (A), uso de cerca para proteção da área de plantio (B).

Por meio deste levantamento pode-se concluir que a silvicultura ainda é uma atividade muito primitiva no meio rural, porem aos poucos poderá obter um crescimento futuro, talvez falte politicas publicas locais que incentive o produtor a não ser dependente somente de cultura anuais, pois nota-se que esses municípios ficam muito presos, e fragilizados dependentes de uma fonte de renda aonde que períodos de seca enfraquecem toda a economia dessas áreas. Com politicas adequadas, e informações pode-se mostrar que a silvicultura é sim uma grande fonte de renda e não tão dependente a fatores temporais, pelo fato de ser mais resistente, quanto as cultura anuais, e que já nos primeiros anos podese obter lucros afim de abastecimento de fábricas para celulose e carvão vegetal. No caso do plantio de pinus ainda tem a resinagem, uma atividade paralela que garante grande lucro.

Ao fim desde estudo foi distribuído panfletos informativos aos agricultores, e informado as prefeituras locais sobre a possibilidade de realização de palestras futuras referentes á silvicultura no Brasil, objetivando dar um enfoque maior os números que esta atividade vem gerando a título de país, com isso pretende-se aumentar a área de plantio de pinus na região.

\section{CONCLUSÃO:}

Com o presente estudo, podemos concluir que a silvicultura ainda é uma atividade primitiva no meio Rural, porém aos poucos está ganhando um crescimento relativo, ocupando áreas aonde a agricultura não se torna viável. Em termos de tecnologias, ainda estamos longe de ser um país desenvolvido no setor florestal, comparado com países como a Finlândia, que apesar de não terem um clima favorável ao crescimento de arbóreas, possuem uma produção muito mais elevada que a nossa. Mediante a esses aspectos vimos que o Brasil ainda é um pais muito atrasado e que talvez politicas 
incentivadoras, e mais acesso a informações seja um caminho para conseguirmos mudar essa realidade, trazendo uma nova alternativa de fonte renda, principalmente no meio rural.

\section{REFERÊNCIAS}

BERTOLANI, F. Programas em andamento e problemas básicos em florestas implantadas de Pinheiros tropicais. In: Congresso IUFRO. Agudos/SP. 1980.

EMPRESA BRASILEIRA DE PESQUISA AGROPECUÁRIA. Centro Nacional de Pesquisa de Florestas, Curitiba, PR. Zoneamento ecológico para plantios florestais no estado de Santa Catarina. Brasília, Departamento de Difusão de Tecnologia, 1988. 113p.

IPEF. Curso de treinamento e atualização em experimentação. Circular Técnica 23. Piracicaba. 26-30 p. 1976.

KRONKA, Francisco J. N.; BERTOLANI, Francisco; PONCE, Reinaldo H. A cultura do pinus no Brasil. São Paulo: Sociedade Brasileira de Silvicultura, 2005.

KWASNIESWSKI, Cristian Marcelo; COELHO, Marcio Henrique. Aspectos econômicos do reflorestamento de pinus na pequena propriedade rural: um estudo de caso. 2008. Trabalho apresentado no $4^{\circ}$ Encontro de Engenharia dos Campos Gerais, Ponta Grossa, 2008.

PILAU, F. G.; ANGELOCCI, L. R.; SCARPARI, J. A. Radiation balance of an orange tree in orchard and its relation with global solar radiation and grass net radiation. RevistaBrasileira de Agrometeorologia, Santa Maria, v.15, n.3, p.257-266, 2007. 